\title{
Toxic manifestation of endosulfan and ochratoxin- a in adult male rats
}

\begin{abstract}
The study examined effects of Ochratoxin-A (OTA) and Endosulfan on the haematobiochemical changes in rats. Adult male Wistar rats were randomly divided into four groups and fed OTA @ 4ppm in feed (Group I); endosulfan @ $5 \mathrm{mg} / \mathrm{kg}$ body weight in corn oil by oral intubation (Group II); combination of both endosulfan @ $5 \mathrm{mg} / \mathrm{kg}$ body weight in corn oil and OTA@4ppm in feed (Group III) and toxin free feed (Group IV - control group) daily for 30 days. After treatment, blood was collected from heart for studying haematobiochemical indices. All toxin treated rats showed a significant $(\mathrm{P}<0.05)$ decrease in the body weights. The treated rats became anemic (normocytic hypochromic anemia) and also revealed lympho cytopenic-leukopenia. Biochemical changes included significant decline in, serum globulin, total protein and albumin along with concurrent increased levels of blood glucose, AST and ALT. Spleen of the treated animals showed depletion of lymphocytes on light microscopy. The present investigation revealed significant toxicity in combination group in comparison to single exposure to OTA or endosulfan alone (Group I and Group II, respectively). These findings suggest that concurrent exposure to endosulfan and OTA results in additive toxic manifestation on haemato-biochemical parameters in male rats.
\end{abstract}

Volume I Issue 3 - 2015

\author{
Shashi Nandar Kumar,' Avinash Gopal \\ Telang, ${ }^{2}$ Karam Pal Singh, ${ }^{2}$ Banajit Bastia,' \\ Arun Kumar Jain' \\ 'Department of Environmental Toxicology, National Institute of \\ Pathology (ICMR), India \\ ${ }^{2}$ Centre for Animal Disease Research and Diagnosis (CADRAD), \\ Indian Veterinary Research Institute, India
}

\author{
Correspondence: Arun Kumar Jain, Department of \\ Environmental Toxicology, National Institute of Pathology \\ (ICMR), Safdarjung Hospital Campus, New Delhi-I I0029, India, \\ Tel +9| || 26|98402, Fax +9| | | 26|9840| \\ Email drakjain@gmail.com
}

Received: May 15, 2014 | Published: July 29, 2015

Keywords: ochratoxin-a (ota), endosulfan, normocytic normochromic anemia, lymphocytopenia, leucopenia

Abbreviations: OTA, ochratoxin-a; HR, hour; PPM, parts-per million; B.Wt., body weight; RBC, red blood cell; Hb, hemoglobin; PCV, packed cell volume; TLC, total leukocyte count; DLC, differential leukocyte count; $\mathrm{MCV}$, mean corpuscular volume; $\mathrm{MCH}$, mean corpuscular hemoglobin; MCHC, mean corpuscular hemoglobin concentration; BUN, blood urea nitrogen; ALP, alkaline phosphatase; ALT, alanine transaminase; AST, aspartate transaminase

\section{Introduction}

Contamination of agricultural produce by pesticides and/or mycotoxins can result in severe problems both for human health as well as the economic value of crops. Mycotoxins are fungal metabolites produced by several molds that contaminate various agricultural commodities during crop production, or in storage, where drying technology may be preventative. Ochratoxin-A (OTA), produced by several species of genera Aspergillus and Penicillium is a common contaminant of different food or feedstuffs which can cause toxicities in human beings and animals. ${ }^{1}$ OTA can result in several deleterious health effects causing - neurotoxicity, ${ }^{2}$ nephrotoxicity, ${ }^{3}$ genotoxicity, ${ }^{4}$ immunotoxicity, ${ }^{5}$ carcinogenicity ${ }^{6}$ and teratogenicity ${ }^{7,8}$ in various mammalian species. Occurrence of OTA has also been reported in humans' serum, breast milk and kidneys suggesting its public health significance. ${ }^{9}$

Pesticides are used to protect crops from damage caused by pests including molds and pathogens. Exposure of the general population to pesticides can occur by direct application to food commodities (to increase their shelf-life) and/or through drinking water contaminated with pesticide residues. ${ }^{10}$ At low level many pesticides have potential toxic effects on non-target organisms and may interfere with the endocrine system. ${ }^{11}$ Endosulfan is one of the most commonly used organochlorine pesticides, which is lipophilic in nature. Because of its persistence in the environment, its usage has been banned in most developed countries. However, it is still being used in the developing countries because of its availability through illegal importation. ${ }^{12}$ The perused literature showed some information on the contamination OTA and endosulfan in adult male rats, ${ }^{4,13}$ but reports on their toxic effects in animals are limited. Moreover, no report could be traced in the literature on the combined effect of OTA and endosulfan in male rats, although both may occur as co-contaminants under field conditions in certain areas. It is with this view that this study was carried out to investigate the combined toxic effects of endosulfan and OTA on the hematological and biochemical indices of male rats.

\section{Materials and methods}

\section{Production and analysis of Ochratoxin-A}

A pure culture of Aspergillus ochraceus NRRL-3174 originally procured from National Centre for Agriculture Research (NCAUR-3174) Peoria, Illinois, USA was grown on sterilized maize as per the method described by Trenk et al. ${ }^{14}$ The extraction and clean up of the toxin sample was done as per the method of AOAC. ${ }^{15}$ Cultured maize powder containing known amount of OTA was added to basal ration in such a proportion that the final concentration of OTA was adjusted to $4 \mathrm{ppm}$ level in the feed..$^{13}$

\section{Animals and experimental design:}

Male Wistar rats $(n=40)$ with average weight $160 \pm 10 \mathrm{~g}$ were procured from Laboratory Animal Resource Section of Indian Veterinary Research Institute (IVRI), Izatnagar, Bareilly, Uttar Pradesh, India. Animals were housed in polypropylene cages in an artificially illuminated room (12-hr light: 12-hr dark cycle) free from any source of chemical contamination. The temperature and relative humidity of the room were maintained at $22 \pm 3^{\circ} \mathrm{C}$ and about 
$50-60 \%$, respectively. Rice bran was used as bedding material which was changed on every alternate day. The rats were provided with standard laboratory animal feed and water ad libitum. After fifteen days of acclimatization period, they were randomly assigned into four groups viz. Group-I, served as a negative control and rats received standard toxin-free feed; Group-II, rats received diet containing OTA alone at a dietary level of 4ppm (as explained above); Group-III, rats received endosulfan alone dissolved in corn oil at a concentration of $5 \mathrm{mg} \mathrm{kg}^{-1}$ b.wt. by oral intubation daily; and Group-IV, rats received both OTA (4ppm) and endosulfan $\left(5 \mathrm{mg} \mathrm{kg}^{-1}\right.$ b.wt.) throughout the experiment. ${ }^{13}$ The experiment on rats was approved by the Animal Ethical Committee of IVRI, Bareilly. The dose selection criteria for the present stud decided on the basis of oral median lethal dose $\left(\mathrm{LD}_{50}\right)$ of OTA (20-30 $\mathrm{mg} \mathrm{kg}^{-1}$ b.wt.) and endosulfan ( $80 \mathrm{mg} \mathrm{kg}^{-1}$ b.wt.) in rats. Considering a rat weighing $160 \mathrm{~g}$, daily consumes about $25 \mathrm{~g}$ diet containing $4 \mu \mathrm{g}$ OTA/g diet, approximately, $1 / 30^{\text {th }}$ oral lethal dose $\left(\mathrm{LD}_{50}\right)$ levels for OTA $(4 \mathrm{ppm})$ and $1 / 15^{\text {th }}$ oral lethal $\left(\mathrm{LD}_{50}\right)$ dose levels for endosulfan $\left(5 \mathrm{mg} \mathrm{kg}^{-1}\right.$ b.wt.) were selected and used in the present investigation.

\section{Hematology}

At the end of the study i.e. after 30 days post-intoxication, the blood samples were collected by cardiac puncture into heparinised vials during the sacrifice of animals. Complete hemogram, including red blood cell count (RBC), hemoglobin (Hb), packed cell volume (PCV), total leukocyte count (TLC), differential leukocyte count (DLC), mean corpuscular volume (MCV), mean corpuscular hemoglobin $(\mathrm{MCH})$, and mean corpuscular hemoglobin concentration (MCHC) were estimated by using standard reference methods of Jain. ${ }^{16}$

\section{Serum biochemistry}

Total serum protein, albumin (modified Biuret \& BCG dye binding methods), blood urea nitrogen (BUN) (DAM method), serum creatinine, serum alkaline phosphatase (ALP), serum alanine transaminase (ALT), serum aspartate transaminase (AST), serum calcium and phosphorus were estimated by Commercial Biochemical kits (Span Diagnostics Ltd. Gujarat, India). The values of globulin were derived by subtracting the values of albumin from that of total protein.

\section{Pathological changes}

Spleen from rats of all the groups was examined for gross changes. Representative tissue samples were collected in $10 \%$ buffered formalin for histopathological studies. The tissue samples were properly processed and embedded in paraffin wax. The sections were stained with routine hematoxylin and eosin $\operatorname{stain}^{17}$ and were then examined under light microscope.

\section{Statistical analysis}

Data generated during the study were suitably analyzed using one way Analysis of Variance (ANOVA) to detect differences among groups and the means were compared by Dunnett's multiple comparison test. All analyses were performed with Graph Pad In Stat software (San Diago, USA). All the statements of significance were based on a probability level of $\mathrm{p}<0.01$.

\section{Results}

There were no noticeable clinical signs and symptoms. During the last two weeks of the experiment, rats from toxin fed group appeared dull, depressed and anorexic. The rats of control group remained active and alert throughout the experiment. Weekly body weight of the rats receiving OTA, endosulfan and their combination for 30 days were recorded. There was significant reduction $(\mathrm{P}<0.05)$ in the body weight of rats given combination of OTA and endosulfan from $1^{\text {st }}$ week onwards and from $2^{\text {nd }}$ week onwards in the rats given OTA alone as compared with control group (Table 1). There was a nonsignificant reduction in weekly body weight of the rats belonging to endosulfan treated group (Table 1). Effect of 30 days treatment with OTA, endosulfan and their combination on various hematological parameters was studied (Table 2). There was significant reduction in the mean hemoglobin $(\mathrm{Hb})$ values of the rats administered OTA, Endosulfan and their combination than those of control. There was marked reduction in $\mathrm{Hb}$ values in combination group as compared to exposure to OTA or endosulfan alone. The PCV values were significantly reduced in rats receiving combination of two toxins as against in control rats. However, there was no reduction in the PCV values when OTA and endosulfan were administered individually to the rats. The values of TLC were significantly lowered in rats receiving OTA, endosulfan and their combination as compared to untreated rats. However, there was no significant difference amongst the three treatment groups. The RBC values remain unaltered due to OTA and Endosulfan treatment from that of untreated control. However, the combination treatment caused significant reduction in the RBC count as compared to remaining three groups. Rats of combination group i.e. (OTA+Endosulfan) showed significant decrease in derived values of $\mathrm{MCV}, \mathrm{MCHC}$ and $\mathrm{MCH}$. On the other hand, in comparison to control, significantly lower values of $\mathrm{MCHC}$ and $\mathrm{MCH}$ were observed in the OTA treated group. Blood leukocytes revealed fragmentation and formation of round globular structures in the cytoplasm indicating apoptosis in all the three experimental groups. Differential Leukocyte Count did not show much variation except neutrophilia (56\%) in OTA group with corresponding lymphocytopenia (36.7\%). The values of several biochemical indices were found to be decreased in all the three treatment groups as compared to control (Table 3). The reduction was registered in levels of serum total protein, albumin, globulin, and calcium and phosphorous. On the contrary levels of serum glucose, ALP, creatinine, ALT, AST and BUN were found to be elevated in the three treatment groups. The variations i.e. increase as well as decreases were more pronounced the combined treatment group IV of OTA+Endosulfan (Table 3).

Table I Effect of OTA (4ppm) and Endosulfan $\left(5 \mathrm{mg} \mathrm{kg}^{-1}\right.$ b.wt) administered alone and in-combination on weekly body weight of adult male rats. Mean bearing at least one common superscript do not differ significantly between groups.

\begin{tabular}{|c|c|c|c|c|c|}
\hline Group $\rightarrow$ & Control & OTA & Endosulfan (ES) & Combination (OTA + ES) & Significance \\
\hline Weeks $\downarrow$ & \multicolumn{5}{|c|}{ Body weight $(\mathrm{gm})$ expressed as Mean \pm SE $(n=10)$} \\
\hline 0 & $155.0 \pm 8.42$ & $156.67 \pm 7.26$ & $156.67 \pm 6.67$ & $158.25 \pm 3.12$ & Non significant \\
\hline $1^{\text {st }}$ & $157.5 \pm 7.77^{\mathrm{b}}$ & $150.0 \pm 7.64$ & $156.0 \pm 3.05$ & $137.5 \pm 3.23^{\mathrm{a}}$ & $P \leq 0.05$ \\
\hline $2^{\text {nd }}$ & $160.25 \pm 7.19^{b}$ & $\mid 38.67 \pm 5.20^{\mathrm{a}}$ & $155.33 \pm 2.67^{\mathrm{b}}$ & $|3| .5 \pm\left. 3.0\right|^{\mathrm{a}}$ & $P \leq 0.05$ \\
\hline $3^{\text {rd }}$ & $165.00 \pm 6.45^{b}$ & $134.33 \pm 5.36^{\mathrm{a}}$ & $151.67 \pm 3.84^{b}$ & $122.5 \pm 3.23^{\mathrm{a}}$ & $P \leq 0.05$ \\
\hline $4^{\text {th }}$ & $171.00 \pm 7.08^{c}$ & $128.67 \pm 4.18^{\mathrm{ab}}$ & $148.33 \pm 5.67^{\mathrm{bc}}$ & $112.5 \pm 2.50^{\mathrm{a}}$ & $P \leq 0.01$ \\
\hline
\end{tabular}


Table 2 Effect of OTA and Endosulfan (ES) administered alone and in combination on hematological parameters (Values expressed as Mean \pm SE; $N=I 0$ ) in adult male rats. Mean bearing at least one common superscript do not differ significantly between groups. ES= Endosulfan

\begin{tabular}{|c|c|c|c|c|c|}
\hline Parameters & Control & $\begin{array}{l}\text { OTA } \\
(4 p p m)\end{array}$ & Endosulfan (5 mg kg-1 b.wt) & Combination (OTA + ES) & Significance \\
\hline Hemoglobin (g/dl) & $13.78 \pm 0.175^{d}$ & $9.22 \pm 0.35^{b}$ & $12.15 \pm 0.48^{c}$ & $7.86 \pm 0.3 \mathrm{I}^{\mathrm{a}}$ & $P \leq 0.01$ \\
\hline PCV (\%) & $40.52 \pm 0.83^{\mathrm{a}}$ & $37.18 \pm 0.95^{\mathrm{a}}$ & $38.56 \pm 1.32^{\mathrm{a}}$ & $31.36 \pm 1.73^{\mathrm{b}}$ & $P \leq 0.01$ \\
\hline $\operatorname{TLC}\left(X \mid 0^{3} / \mu l\right)$ & $12.74 \pm 44^{b}$ & $10.42 \pm 0.54^{\mathrm{ab}}$ & $11.5 I \pm 0.50^{\mathrm{a}}$ & $10.13 \pm 1.11^{\mathrm{a}}$ & $P \leq 0.05$ \\
\hline $\operatorname{RBC}\left(10^{6} / \mu \mid\right)$ & $6.62 \pm 0.155^{\mathrm{b}}$ & $6.12 \pm 0.172^{b}$ & $6.43 \pm 0.22^{b}$ & $5.29 \pm 0.29^{a}$ & $P \leq 0.01$ \\
\hline $\mathrm{MCV}(\mathrm{fL})$ & $60.94 \pm 0.60^{\mathrm{b}}$ & $60.73 \pm 0.48^{b}$ & $60.76 \pm 0.36^{\mathrm{b}}$ & $58.19 \pm 1.27^{a}$ & $P \leq 0.05$ \\
\hline $\mathrm{MCHC}(\%)$ & $34.3 I \pm 0.77^{c}$ & $23.58 \pm 0.90^{\mathrm{a}}$ & $31.86 \pm 1.77^{\mathrm{bc}}$ & $27.10 \pm 1.85^{\mathrm{ab}}$ & $P \leq 0.01$ \\
\hline $\mathrm{MCH}(\mathrm{pg})$ & $20.80 \pm 0.44^{b}$ & $14.28 \pm 0.57^{\mathrm{b}}$ & $19.11 \pm 0.98^{b}$ & $14.73 \pm 1.27^{\mathrm{a}}$ & $P \leq 0.01$ \\
\hline Neutrophil (\%) & $31.30 \pm 0.70^{\mathrm{a}}$ & $56.0 \pm 1.0 \mathrm{I}^{\mathrm{b}}$ & $29.5 \pm 0.909^{a}$ & $30.60 \pm 0.83^{\mathrm{a}}$ & $P \leq 0.01$ \\
\hline Lymphocyte (\%) & $65.30 \pm 0.47^{a}$ & $36.70 \pm 0.87^{a}$ & $65.70 \pm 0.67^{\mathrm{a}}$ & $64.9 \pm 0.90^{\mathrm{a}}$ & $P \leq 0.0 \mathrm{I}$ \\
\hline Monocyte (\%) & $1.60 \pm 0.27^{\mathrm{a}}$ & $5.00 \pm 0.47^{c}$ & $2.40 \pm 0.16^{\mathrm{ab}}$ & $3.70 \pm 0.47^{\mathrm{bc}}$ & $P \leq 0.01$ \\
\hline Eosinophil (\%) & $1.00 \pm 0.42^{\mathrm{a}}$ & $2.00 \pm 0.26^{\mathrm{ab}}$ & $2.4 \pm 0.37^{b}$ & $1.0 \pm 0.25^{a}$ & $P \leq 0.0 \mathrm{I}$ \\
\hline Basophils (\%) & $0.80 \pm 0.25^{a}$ & $0.0^{\mathrm{b}}$ & $0.0^{\mathrm{b}}$ & $0.0^{\mathrm{b}}$ & $P \leq 0.01$ \\
\hline
\end{tabular}

Table 3 Effect of OTA and Endosulfan (ES) administered alone and in combination on biochemical parameters in adult male rats.

\begin{tabular}{|c|c|c|c|c|c|}
\hline Parameters & Control & $\begin{array}{l}\text { OTA } \\
(4 \mathrm{ppm})\end{array}$ & Endosulfan (5mg kg-1 b.wt) & Combination (OTA + ES) & Significance \\
\hline Glucose (mg/dl) & $80.13 \pm 2.10^{\mathrm{a}}$ & $100.23 \pm 2.38^{\mathrm{b}}$ & $100.38 \pm 1.58^{\mathrm{b}}$ & $115.07 \pm 1.89^{\circ}$ & $P \leq 0.01$ \\
\hline Total protein $(g / d l)$ & $7.82 \pm 0.204^{b}$ & $6.58 \pm 0.365^{\mathrm{ab}}$ & $7.22 \pm 0.37^{\mathrm{ab}}$ & $6.29 \pm 0.34^{a}$ & $P \leq 0.01$ \\
\hline Albumin $(\mathrm{g} / \mathrm{dl})$ & $4.34 \pm 0.153^{b}$ & $3.62 \pm 0.233^{\mathrm{ab}}$ & $4.05 \pm 0.223^{b}$ & $3.08 \pm 0.244^{\mathrm{a}}$ & $P \leq 0.01$ \\
\hline Globulin (g/dl) & $3.59 \pm 0.280^{b}$ & $2.603 \pm 0.29^{\mathrm{a}}$ & $2.55 \pm 0.337^{\mathrm{a}}$ & $2.66 \pm 0.268^{\mathrm{a}}$ & $P \leq 0.05$ \\
\hline AG ratio & $1.84 \pm 0.075$ & $1.86 \pm 0.107$ & $1.78 \pm 0.17$ & $1.95 \pm 0.21$ & Non significant \\
\hline ALP (IU/L) & $84.6 \pm 0.194^{\mathrm{a}}$ & $106.7 \pm 0.62^{b}$ & $104.7 \pm 0.726^{b}$ & $117.0 \pm 0.92^{b}$ & $P \leq 0.05$ \\
\hline Creatinine (mg/dl) & $1.07 \pm 0.060^{\mathrm{a}}$ & $1.87 \pm 0.193^{\mathrm{bc}}$ & $1.51 \pm 0.18^{\mathrm{ab}}$ & $2.26 \pm 0.227^{c}$ & $\mathrm{P} \leq 0.0 \mathrm{I}$ \\
\hline Calcium (mg/dl) & $9.36 \pm 0.23^{b}$ & $8.84 \pm 0.23 \mathrm{a}^{\mathrm{b}}$ & $8.97 \pm 0.23^{\mathrm{ab}}$ & $8.33 \pm 0.17^{a}$ & $P \leq 0.01$ \\
\hline Phosphorus (mg/dl) & $8.49 \pm 0.224^{b}$ & $8.07 \pm 0.24 \mathrm{a}^{\mathrm{b}}$ & $8.00 \pm 0.21^{\mathrm{ab}}$ & $7.59 \pm 0.196^{\mathrm{a}}$ & $P \leq 0.01$ \\
\hline BUN (mg/dl) & $19.52 \pm 0.52^{\mathrm{a}}$ & $24.01 \pm 0.68 b^{c}$ & $21.99 \pm 0.567^{\mathrm{ab}}$ & $26.00 \pm 0.92^{c}$ & $P \leq 0.01$ \\
\hline ALT (U/L) & $79.17 \pm 3.082^{\mathrm{a}}$ & $103.81 \pm 2.58^{\mathrm{b}}$ & $94.32 \pm 3.04 I^{b}$ & $133.16 \pm 2.93^{c}$ & $P \leq 0.01$ \\
\hline AST (U/L) & $87.68 \pm 1.74^{a}$ & $96.27 \pm 3.89^{a}$ & $103.18 \pm 3.76^{a}$ & $144.45 \pm 9.28^{b}$ & $P \leq 0.01$ \\
\hline
\end{tabular}

Values expressed as Mean $\pm \mathrm{SE}(\mathrm{N}=10)$

Mean bearing at least one common superscript do not differ significantly between groups. ES= Endosulfan.

While samples of spleen from control animals showed the presence of parenchyma with mild hemosiderin pigment on light microscopy, sections from OTA and endosulfan treated animals showed focal depletion of lymphocytes in some of the peri-arteriolar lymphoid tissue and hemosiderin deposit in parenchyma (Figure $1 \& 2$ ). Animals exposed to Endosulfan and OTA combination had splenic corpuscles with poor population of lymphoid cells along with presence of hemosiderin pigment (Figure 3). 


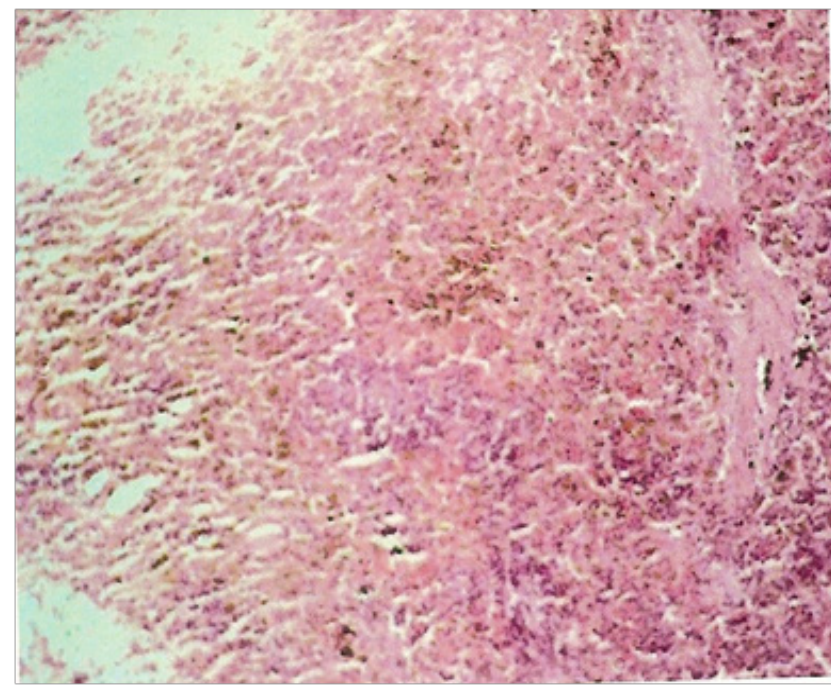

Figure I Spleen from OTA treated rat shows haemosiderin pigmentation and poor population of lymphoid cells in white pulp ( $\mathrm{H} \& \mathrm{E}, \mathrm{I00X})$.

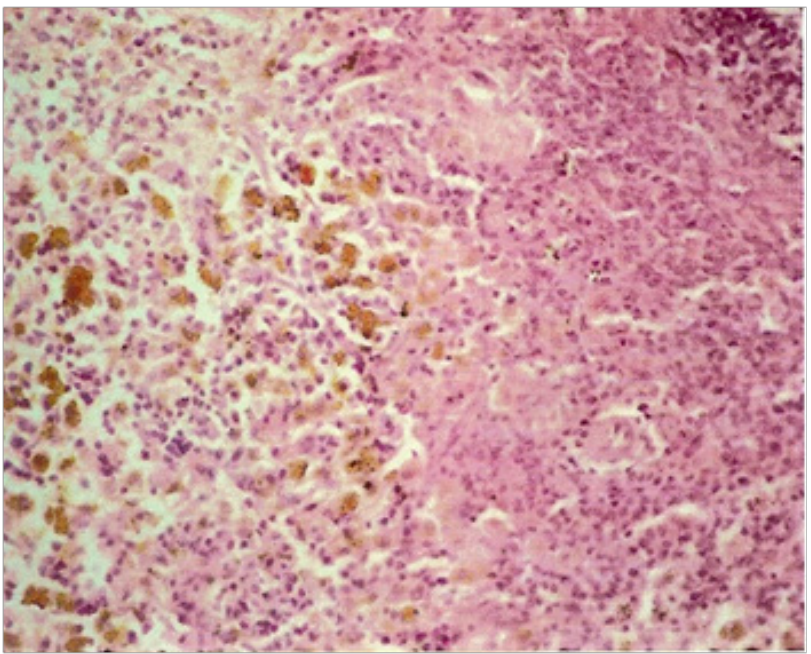

Figure 2 Light micrograph from endosulfan treated animal shows haemosiderin deposits and mild depletion of lymphoid cells in peri-arteriolar lymphoid tissue (H \& E, 200X).

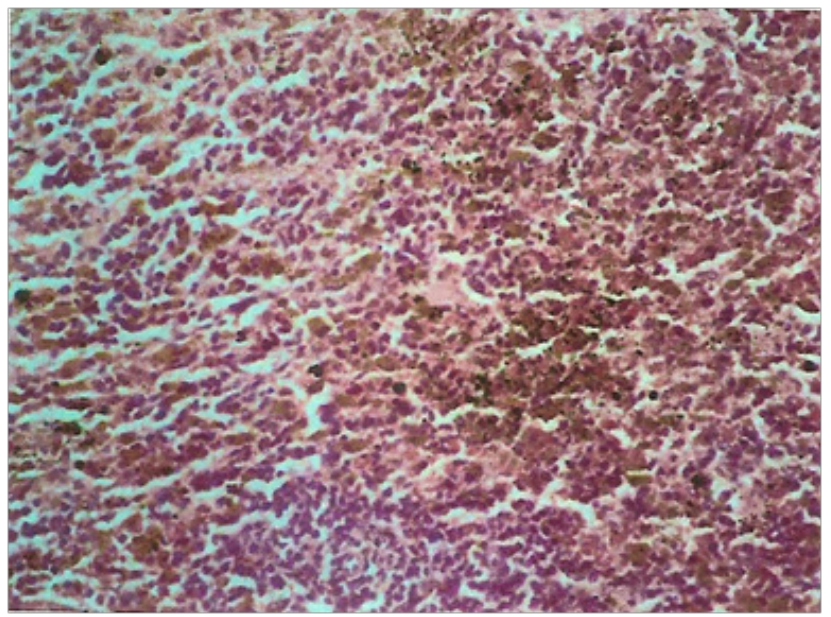

Figure 3 Micrograph of spleen from endosulfan + OTA treated rat. The splenic corpuscles show poor population of lymphoid cells along with prominent haemosiderin pigment in parenchyma (H \& E, 200X).

\section{Discussion}

In this study, the rats of the control group as well as all the three experimental groups weighed approximately 150 to 160 gm on day zero. As expected the control rats gained weight during 4-weeks experiment and their weight increased to $171 \pm 7 \mathrm{gm}$. In the treatment groups, however, all the rats showed variable decline in the weight during the course of experiment and the lowest body weight was recorded in combination group treated with endosulfan and OTA. Our finding on reduction weight are consistent are with previous reports. ${ }^{18,19}$ The study further revealed OTA-induced normocytic hypochromic anemia. There was also reduction in total leukocyte count marked by lymphocytopenia along with increase in neutrophil percentage. The literature available regarding the effects of OTA on hematological parameters is contradictory and inconsistent. ${ }^{20,21}$ Mild leukocytopenia and lymphocytopenia observed in the present study could be associated with lymphoid cell depletion from lymphoid organs as observed during histopathological examination of spleen. OTA-induced leukocytopenia associated with lymphocytopenia has been reported previously in several experimental animals including rats. $^{22}$ Endosulfan caused the lymphocytopenic leukocytopenia, which were reported in mice. ${ }^{23}$ Reduction in hemoglobin and PCV values, suggestive of anemia in the present study are in accordance with earlier reports in poultry, ${ }^{24}$ mice ${ }^{23}$ and pregnant rat. ${ }^{25}$ Anemia might be attributed to low nutrition intake, reduced protein synthesis and increased protein excretion in urine. Leukocytopenia was essentially lymphocytopenia type which might be correlated with decreased number of lymphocytes in spleen and Peyer's patches seen histopathologically. Similar changes of mild depletion of lymphocytes in spleen have also been reported. ${ }^{26}$ The anemia was more pronounced in OTA and endosulfan combination group probably due to their synergistic effects on heamatopoietic system.

Biochemical alterations in OTA treated rats were decrease in serum total protein, albumin, globulin, calcium and phosphorus levels. Decreased serum total protein, albumin, globulin values might be due to OTA-induced damage to liver, ${ }^{27}$ the major site of protein synthesis. ${ }^{28,29}$ OTA has been shown to inhibit the protein synthesis. Further, proteinuria especially albuminuria resulting from toxic damage to nephrons could have resulted in decreased albumin fraction observed in the study and corresponding reduction of $\mathrm{A}: \mathrm{G}$ ratio. ${ }^{30}$ Decrease in calcium and phosphorus levels is in agreement with reported decline in OTA-treated Broiler chicken. ${ }^{31,32}$ Along with reduction in protein, calcium and phosphorus, OTA toxicity resulted in significant increase in the blood glucose levels. This finding was akin to the report of the earlier workers in $\operatorname{rats}^{33}$ and pig $^{29}$ who recorded increase in blood glucose level in ochratoxicosis. It is possible that the depletion of glycogen from liver might have resulted in increased blood glucose levels. ${ }^{34}$ Hyperglycemia in ochratoxicosis may be due to the inhibited synthesis and/or reduced release of insulin from the pancreatic cell..$^{33}$

Rats receiving endosulfan by oral intubation also showed decrease in serum total protein, albumin, globulin, calcium and phosphorous and the increase in levels of glucose, ALP, ALT, AST and BUN which is in accordance with the previous publications. ${ }^{31}$ Decrease in total protein values might be due to low feed intake, inadequate digestion and/or absorption due to endosulfan induced damage in gastrointestinal tract, ${ }^{13}$ liver damage, anorexia and hepatotoxic activity of endosulfan. ${ }^{35}$ As in the case of OTA-induced toxicity, severe damage to nephrons could result in proteinuria especially albuminuria thereby causing decrease in serum albumin fraction and corresponding reduction in A:G ratio. Decrease in levels of calcium and phosphorous 
has also been reported earlier. ${ }^{36}$ Increased blood urea nitrogen (BUN) may be due to prerenal causes (cardiac decompensation, water depletion due to decreased intake, and increased protein catabolism) or renal causes (tubular necrosis) and is in agreement with earlier reports in rats. ${ }^{35,37}$ Significantly increased blood glucose level in OTA and endosulfan treated animals is in agreement with the previous findings of increased blood glucose level after oral endosulfan and dimethoate administration ${ }^{38,39}$ and could be due to decreased level of insulin synthesis from pancreatic cells, increase in glucogenesis and glycogenolysis as well as inhibition of glucogenolysis and glycogenesis during stress. ${ }^{40}$

\section{Conclusion}

It can be deduced from this study that individual as well as combined exposure of OTA and endosulfan has the potential to damage the structural integrity and physiological activities of the organism which led to changes in haemato-biochemical parameters. Further, concomitant exposure to more than one toxin may result in additive toxic manifestations.

\section{Acknowledgements}

None.

\section{Conflict of interest}

The authors declared no potential conflicts of interest with respect to the authorship and/or publication of this article.

\section{References}

1. Milicevic DR, Skrinjar M, Baltic T. Real and perceived risks for mycotoxin contamination in foods and feeds: challenges for food safety control. Toxins (Basel). 2010;2(4):572-592.

2. Zhang X, Boesch-Saadatmandi C, Lou Y, et al. Ochratoxin A induces apoptosis in neuronal cells. Genes Nutr. 2009;4(1):41-48.

3. Rahimtula AD, Chong X. Alterations in calcium homeostasis as a possible cause of ochratoxin A nephrotoxicity. IARC Sci Publ. 1991;115:207-214.

4. Kumar SN, Telang AG, Patil DR, et al. Cytogenetic effects of combined Ochratoxin A and Endosulfan in Rats. $J$ Environ Anal Toxicol. 2014;4:217.

5. Alvarez L, Gil AG, Ezpeleta O, et al. Immunotoxic effects of Ochratoxin A in Wistar rats after oral administration. Food Chem Toxicol. 2004;42(5):825-834.

6. Pfohl-Leszkowicz A, Manderville RA. Ochratoxin A: An overview on toxicity and carcinogenicity in animals and humans. Mol Nutr Food Res. 2007;51(1):61-99.

7. Wangikar PB, Dwivedi P, Sinha N, et al. Teratogenic effects in rabbits of simultaneous exposure to ochratoxin A and aflatoxin B1 with special reference to microscopic effects. Toxicology. 2005;215(1-2):37-47.

8. Malir F, Ostry V, Pfohl-Leszkowicz A, et al. Ochratoxin A: developmental and reproductive toxicity-an overview. Birth Defects Res B Dev Reprod Toxicol. 2013;98(6):493-502.

9. Biasucci G, Calabrese G, Di Giuseppe R, et al. The presence of ochratoxin A in cord serum and in human milk and its correspondence with maternal dietary habits. Eur J Nutr. 2011;50(3):211-218.

10. Damalas CA, Eleftherohorinos IG. Pesticide exposure, safety issues, and risk assessment indicators. Int $J$ Environ Res Public Health. 2011;8(5):1402-1419.
11. Aktar MW, Sengupta D, Chowdhury A. Impact of pesticides use in agriculture: their benefits and hazards. Interdiscip Toxicol. 2009;2(1):112 .

12. Yekeen TA, Fawole OO. Toxic effects of endosulfan on hematological and biochemical indices of Clarias gariepinus. African Journal of biotechnology. 2011;10(64):14090-14096.

13. Kumar SN, Telang AG, Patil RD, et al. Study on combined effects of ochratoxin A and endosulfan on antioxidant enzymes in rats. Journal of Environmental Biology. 2015;36:601-605.

14. Trenk HL, Butz ME, Chu FS. Production of ochratoxins in different cereal products by Aspergillus ochraceus. Appl Microbiol. 1971;21(6):10321035 .

15. AOAC. Official Method of Analysis. 16th ed. USA: Association of Official Analytical Chemists; 1995.

16. Jain NC. Schalm's Veterinary Hematology. 4th ed. USA: Pub. Lea and Fabiger; 1986.

17. Luna LG. Manual of Histologic Staining Methods of the Armed Forces Institute of Pathology. 3rd ed. USA: Mc Graw Hill Book Co; 1968.

18. Manafi M, Umakantha, Noor Ali M, et al. Study of the Combination Effects of Aflatoxin and T-2 Toxin on Performance Parameters and Internal Organs of Commercial Broilers. Global Veterinaria. 2012;8(4):393-396.

19. Singh ND, Sharma AK, Dwivedi P, et al. Citrinin and endosulfan induced maternal toxicity in pregnant Wistar rats: pathomorphological study. J Appl Toxicol. 2007;27(6):589-601.

20. Singh GS, Chauhan HV, Jha GJ, et al. Immuno suppression due to chronic ochratoxicosis in broiler chicks. J Comp Pathol. 1990;103(4):399-410.

21. Harvey RB, Elissalde MH, Kubena LF, et al. Immuno toxicity of Ochratoxin A to growing gilts. Am J Vet Res. 1992;53(10):1966-1970.

22. Mally A, Volkel W, Amberg A, et al. Functional, biochemical, and pathological effects of repeated oral administration of ochratoxin A to rats. Chem Res Toxicol. 2005;18(8):1242-1252.

23. Arshad N, Yunus S, Adan GE. Endosulfan induced changes in haematological and some immunologial parameters in mice. Punjab Univ J Zool. 2001;16:147-154.

24. Selvaraj J, Balasubramaniam GA, George VI, et al. Effect of dietary endosulfan on the growth rate of broiler chicken. Indian Vet J. 2001;78(9):798-800.

25. Singh ND, Sharma AK, Dwivedi P, et al. Toxicity of endosulfan and Citrinin alone and in combination in pregnant rats: Clinicohaematological and serum biochemical alterations. Indian J Vet Path. 2006;30(1):27-31.

26. Satheesh CC, Sharma AK, Dwivedi P, et al. Immunosuppressive Effect of Ochratoxin A in Wistar Rats. Journal of Animal and Veterinary Advances. 2005;4(6):603-609.

27. Benjamin MM. Outline of Veterinary Clinical Pathology. 3rd ed. USA: Lowa State University; 1985.

28. Krogh P, Axelsen NH, Elling F, et al. Experimental porcine nephropathy. Changes of renal function and structure induced by ochratoxin Acontaminated feed. Acta Pathol Microbiol Scand. 1974;(Suppl 246):121.

29. Stoev SD, Paskalev M, MacDonald S, et al. Experimental one year ochratoxin A toxicosis in pigs. Exp Toxicol Pathol. 2002;53(6):481-487.

30. Prasanna K, Sharma AK, Dwivedi P, et al. Pathogenesis of ochratoxinA induced nephropathy in rats with special reference to oxidative damage, cytokine profile and ultrastructural changes. Indian Journal of Veterinary Pathology. 2007;31(1):1-10. 
31. Gupta S, Jindal N, Khokhar RS, et al. Effect of ochratoxin A on broiler chicks challenged with Salmonella gallinarum. Br Poult Sci. 2005;46(4):443-450.

32. Kubena LF, Harvey RB, Huff WF, et al. Influence of Ochratoxin A and T-2 toxin singly and in combination on broiler chickens. Poultry Sci. 1989;68(7):867-872.

33. Subramanian S, Kanthasamy AS, Blasubramanian N, et al. Dibatogenic nature of ochratoxin A. Curr Sci. 1989;58:878-878.

34. Subramanian S, Govindasamy S. Aspergillus ochraceus toxicity on carbohydrate metabolism in chicks. Cur Sci. 1985;17:860-872.

35. Choudhary N, Sharma M, Verma P, et al. Hepato and nephrotoxicity in rat exposed to endosulfan. J Environ Biol. 2003;24(3):305-308.

36. Reddy BN, Nusrath M, Kumari CK, et al. Mycotoxin contamination in some food commodities from tribal areas of Medak District, Andhra Pradesh. Indian Phytopath. 1986;36(4):683-686.
37. Kiran R, Varma MN. Biochemical studies on endosulfan toxicity in different age groups of rats. Toxicol Lett. 1988;44(3):247-252.

38. Garg A, Kunwar K, Das N, et al. Endosulfan intoxication: Blood glucose, electrolytes, Ca levels, ascsorbic acid and glutathione in rats. Toxicol Lett. 1980;5(2):119-123.

39. Hagar HH, Azza H, Fahmy. A biochemical, histochemical and ultrastructural evaluation of the effect of dimethoate intoxication on rat pancreas. Toxicol Lett. 2002;133(2-3):161-170.

40. Yekeen TA. Studies on the toxic effects of some pyrethroid pesticides using catfish (Clarias gariepinus) and rat (Rattus novegicus) as test organisms. Nigeria: A Ph. D. Thesis submitted to Department of Pure and Applied Biology, Ladoke Akintola University of Technology; 2009. $223 \mathrm{p}$. 